\title{
Understanding Collaborative Teaching and Learning in Adult Literacy: Practices in Canada and the United Kingdom
}

\author{
MAURICE TAYLOR, KAREN EVANS and ALI ABASI
}

\begin{abstract}
The purpose of this study was to investigate how adult students learn collaboratively with other peers in both formal and non-formal adult literacy programs and what teaching styles best support this learning. A multi-site case study research design was used involving several different literacy organizations in Eastern Ontario, Canada, and in Central London, United Kingdom. Findings suggest that collaborative learning is the cement that bonds the various building blocks in a community of literacy practice across small, large and tutorial types of programs. Central in this framework is the component called the Instructor's Philosophy and Teaching Perspective which helps explain the teaching and learning transactions.
\end{abstract}

\section{Introduction}

Increased demands for information-based economies and societies in developed countries have put the spotlight on those adults who are lacking literacy skills. Although adult literacy statistics vary from country to country, it is quite clear that there are more people living today with low literacy skills than there were a decade ago (Statistics Canada 2005). Both Canada and the United Kingdom share similar literacy challenges, policy initiatives and program delivery systems. As well, at the national government policy level, adult literacy is presently occupying public interest in both countries. It was this background that fueled the need to investigate the major components of the teaching and learning transaction across diverse types of adult literacy programs in selected regions of Ontario and in Central London, United Kingdom. The key questions for the study were: 1) How do adult students use collaborative learning with other peers in a wide range of adult literacy provisions? and 2) What teaching styles best support collaborative learning practices among adult students?

The theoretical framework for the study is grounded in two literatures. The first part of the framework is nested in a socio-cultural approach which posits that learning is shaped by the context, culture and tools in the learning situation (O'Connor 1998, Vygotsky 1999, Barton, Hamilton and Ivanic 2000, Hurby 2001, Maloch 2002). This work on 
human cognition attributes all human higher mental functioning, including literacy, to semiotically mediated social interactions of the individual with more knowledgeable peers. In a literacy context, such a process of learning foregrounds collaboration among learners with different literacy skills. Although these socio-cultural frameworks have been widely used in framing school-based pedagogy, only recently have they helped explain adult education practices and in particular adult literacy learning. For example, Taylor, King, Pinsent-Johnson and Lothian (2003) found that adult literacy students act as scaffold builders with other peers in formal literacy programs. They found that social learning behaviours, negotiation and feedback behaviours, central to the notion of collaborative learning among adult peers, were important literacy practices. The authors go on to suggest that with such empirical evidence, it seems likely that learning concepts like cognitive apprenticeships, communities of practice and social literacy may further explain adult literacy learning in different types of programs (Rogoff 1995, Taylor and Blunt 2001, Wenger, McDermott and Snyder 2002).

The second part of the framework for this paper draws from the literature on teaching styles and is grounded in the domain of teaching philosophy and the roles of instructors in adult education. Galbraith (2004) states that becoming an effective teacher of adults depends on acquiring a balance between an appropriate philosophical vision of teaching and the understanding and implementation of that vision into a practical instructional process. In a similar vein, Zinn (2004) maintains that every teacher, when working with adults, has a philosophical orientation and a preferred teaching style, although at times it may be difficult to identify. Pratt (2002) has added a further dimension with respect to why teachers work as they do. He says that teachers come to their practice with a set of values, a perspective, interrelated beliefs and intentions which give meaning and justification to their actions. Pratt identifies five distinct teaching perspectives: transmission, which focuses on delivering content; apprenticeship, which models ways of working; developmental agendas, which cultivate ways of thinking; nurturing, which facilitates personal agency, and social reform, which seeks to create a better society. Some early evidence now exists in adult basic education where researchers found that teachers who support a collaborative learning style in literacy environments had specific assumptions concerning the makeup of knowledge, the purpose of curriculum, the role of the teacher and the role of the learner (Taylor, Abasi, Pinsent-Johnson and Evans 2007).

\section{Methodology}

The methodology for this investigation used a mixed research design employing both qualitative and quantitative strategies with a range of data collection methods and data analysis techniques. Eight different types of 
adult literacy programs were chosen. Five programs were chosen in Eastern Ontario, Canada and three workplace basic skills programs in public sector organizations were chosen in Central London, United Kingdom. Program sites and delivery models included multi-level literacy classrooms, same level literacy classrooms, small literacy group with volunteers, tutorial with volunteers and multi-level classroom with prescribed curriculum. Data was collected in two four-month periods over two years.

Five data sources in both countries were used to answer the first research question: How do adult students use collaborative learning with other peers in a wide range of adult literacy provisions? These sources included participant observations, semi-structured interviews with learners and instructors, focus groups with learners, and documents from each program site. For the Canadian data collection, a video recording was made during the participant observations for each site. This recording included approximately one hour of collaborative learning interactions among students and teachers. During the interview process, the video clips were used to probe deeper into the dynamics of the learning process.

Three data sources were used to answer the second research question: What teaching styles best support collaborative learning among adult students? The sources included the administration of the Teaching Perspectives Inventory, semi-structured interviews with instructors and documents. For the qualitative strategies, the data sources were transformed into research narratives, member checked and subjected to analysis using techniques such as constant comparative (Merriam 2002). For quantitative strategies, Teaching Perspectives Inventory (TPI) profile scores and biographical variables were subjected to various statistical techniques such as one-way analysis of variance, discriminant analysis and multiple regression. Based on the data sets from both countries, an integrated collaborative model was constructed, presented in diagrammatic form as Figure 1 below.

\section{Interpretation of model}

This collaborative teaching and learning model, as presented in Figure 1, reflects a number of literacy practices that are embedded in a specific cultural context and mediated by the personal circumstances of both the learners and the instructors. In other words, each learning situation is unique but has certain common elements that are fluid and are in constant motion. These common elements, identified in the model, will be discussed individually. 


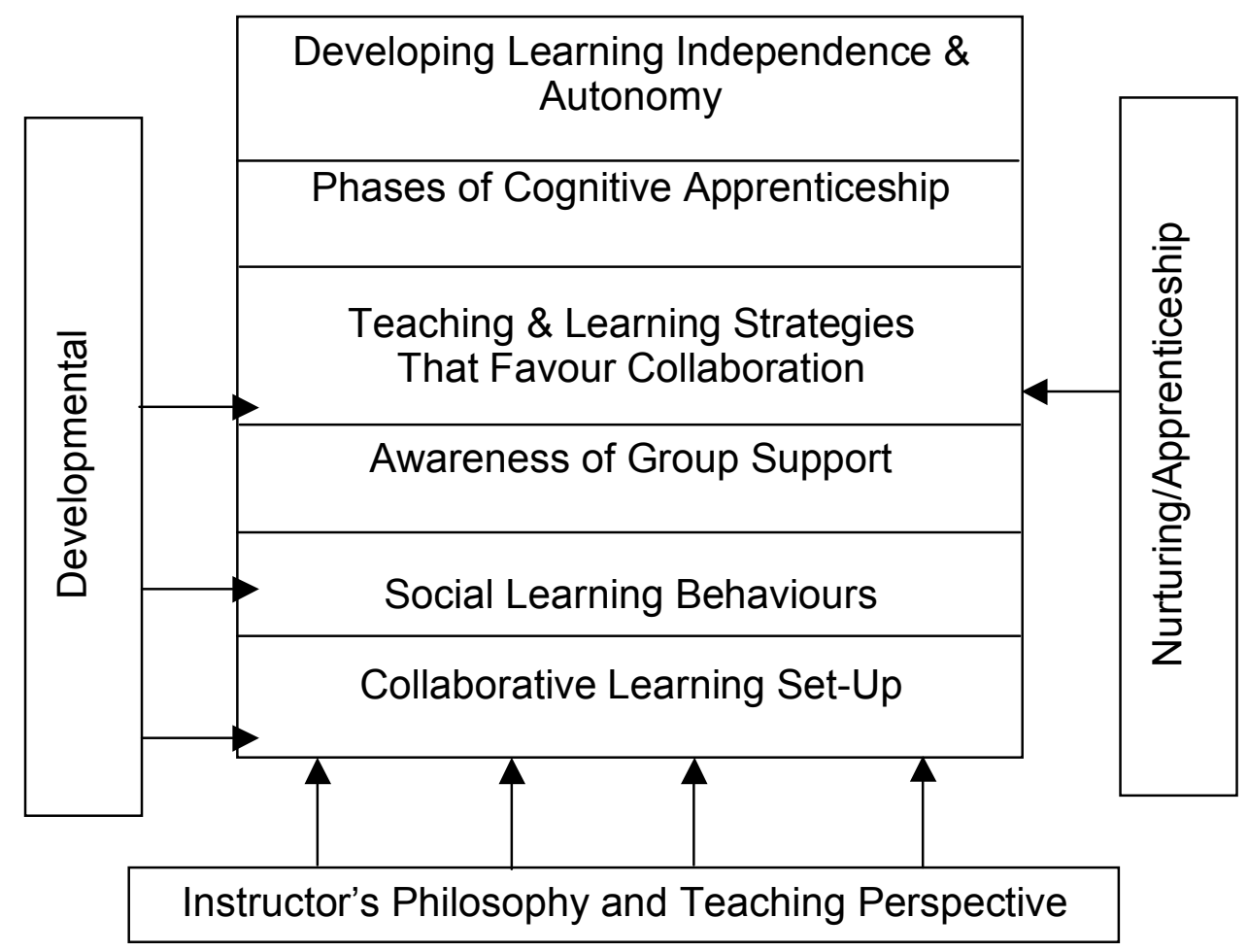

Figure 1: Collaborative teaching and learning model in adult literacy

\section{Instructor's Philosophy and Teaching Perspective}

A central component in the model that helps explain the collaborative teaching and learning transaction is called the Instructor's Philosophy and Teaching Perspective. It encompasses the instructor's philosophical orientation towards adult education and the values, intentions and actions of the instructor. Instructors have certain conceptions of their roles, the nature of learning and ideas about how student learning can be supported. To understand what teaching philosophies (Pratt 2002, Zinn 2004) provide the best environment for a collaborative community of learners, there was a need to explore the participating instructors' philosophies of teaching to see if their beliefs, intentions, and practices have any bearing on their approach to teaching. For this purpose, a Collaborativity Index with three levels of High, Medium and Low was developed (see Taylor, Evans and Abasi 2006). 
Subsequently, ANOVAs were conducted with the three levels of the Collaborativity Index, the five teaching perspectives (TPI), and other variables such as instructors' gender and type of literacy delivery context (formal or non-formal), to capture the interactions among all of the variables. Results indicated, for example, that differences in TPI scores suggest differences in Collaborativity: most so in terms of Developmental ( $F$ $=10.380$, df 2,56, p. 000) but also in terms of Nurturing $(\mathrm{F}=4.248$, df 2,56, p. 019) and Apprenticeship ( $F=3,510$, df 2,56, p. 037). This suggests that those literacy instructors who had high collaborativity indices also scored higher on the Developmental perspective. What this means is that those instructors whose dominant approach to teaching was Developmental, and to a lesser extent Nurturing, tended to follow a collaborative approach. In other words, those instructors who tended to take into account learners' experiences and their ways of understanding and who viewed their role as facilitator of learners' independent meaning-making tended to utilise a collaborative style of teaching.

This finding is further supported by the in-depth interviews with the instructors. For example, one instructor with a high score on the Developmental perspective of the TPI as well as the Collaborativity Index, described how she encouraged new ways of thinking through problems in her small group by saying ' $\mathrm{My}$ teaching] is a process of taking them out, you know, allow them to make mistakes because that's part of learning.' Furthermore, the Developmental perspective appears to be the teaching philosophy that provides the necessary context for learners to work and learn collaboratively. For instance, one key feature of the Developmental perspective is the use of the constructivist approach. One instructor who favoured this style described it this way:

I feel I'm very student-centred. That's the way I like to operate my class. I mean of course there's some direct teaching involved. I always leave a lot of flexibility to address anything coming from my students: extra time, a new concept, extra practice, questions, that sort of thing. I take my cues from them. I have lots of group discussions. I always ask for opinions from the students.

Qualitative observations from the UK data have highlighted some interesting differences in the TP1 profiles that may also merit further investigation. The tutors in the London sample were all work-based instructors supporting literacy learning in workplaces. In such programs, the complexities of scheduling classes around work patterns, different work sites and personal commitments means that breaking down classes into levels of ability is rarely feasible. Tutors were well aware of the varying levels of ability of learners in their groups and skilfully used this knowledge to 
facilitate learning to promote a collaborative approach. The London tutors engaged in collaborative practice shared a dominant nurturing profile on the TPI, and a belief in building trust and confidence amongst learners to create a climate conducive to learning. While nurturing was dominant, the profiles were relatively flat, with significant scores in all other categories except social reform. The more mixed profiles may be explained by the effects on practice of workplace cultures and constraints, together with the more structured, mandatory literacy curriculum frameworks in which UK literacy tutors have to work. These combine to influence tutor's beliefs, intentions and scope for action in complex ways. As one tutor explained:

I think that the tutor should be clear about the purpose of both the lesson and the tasks. I try to build up positive experiences in reading, writing and oral skills and create a safe environment to ask questions. I take them through an ordered structured path.

Based on both Canadian and UK data, the instructor's philosophy and teaching perspective is the cement that bonds the various building blocks in a community of literacy practice across small, large and tutorial types of programs.

\section{Collaborative learning set-up and social learning practices}

As an adult student walks into a literacy program, he or she is greeted with a set-up for supportive learning that is often arranged by the instructor. The teacher may decide to pair learners in a one-on-one match or to organise them in small groups. Instructors rely on their knowledge of individual learner's needs, strengths and characteristics to make these decisions. For instance, in one formal literacy program aimed towards employment, the instructor grouped two learners, Julia and Fatima, based on their linguistic and cultural backgrounds. As the instructor explained:

These two ladies ... this is their first year as well and they're very capable, especially fulia. She is American-born and English is her first language and she's very familiar with the recipes. She just stepped into that leadership role right there that we love to see and she's only been in the program since the middle of September.

In another program, the instructors had grouped three students together, Jane, Paul and Mike. The instructor described Mike as a new student, and from his intake interview information she had recognised him as a strong reader, while the other two students in the group who had been in the program for three to four months had problems with decoding skills 
which is an integral part of the reading process. She had purposely grouped these three students together, so that Mike would be able to coach the other two students when they encountered problems in the reading exercises At the same time, Jane and Paul could help Mike in finding the topic and main idea, and identifying irrelevant sentences from reading passages as he needed practice with these skills

Deciding who to work with in a supportive environment initiates the social learning behaviour of negotiation, in this small literacy community. Negotiation is an important democratic opportunity for adults to accommodate their own interests and goals for participating in such a program. These negotiation practices are often complex and involve evaluation of learners' own learning needs, their perceptions of the abilities of peers, and decisions about who in the group has common learning goals and common cultural and life experiences. In one formal program, five female learners were working in a small group. As one of the learners pointed out,

We are all immigrants and we understand each other; even if you don't understand the language. Immigrants understand themselves. In our group one speaks Arabic, one Persian, two Somalian, one Spanish. Also we are all moms and have the same problems. We're all parents with the same needs, same problems, situations you know.

Given the diversity of learner abilities, these negotiation practices can vary from day to day, and week to week, depending on the group composition and the literacy content. What is important is that these practices help bind individuals together early in the learning process and influence the ongoing nature of the learner-to-teacher interactions and the learner-to-learner interactions.

\section{Awareness of group support}

The next component in the model is awareness of group support. Literacy learners often bring with them certain beliefs about how they should be taught as well as how they should learn. They frequently see learning as an individual academic activity where the teacher is perceived to be the source of all knowledge. When learners witness the difference between the transmission mode of teaching and a more collaborative class, they initially experience frustration and often resist participating in such learning activities. As one instructor pointed out:

Students who come to us from very traditional academic environments [expect] there should be a specific exercise and a book that can be evaluated 
and they can understand that and they can relate to it .... They get upset and say they are wasting their time.

However, as learners start to experience a sense of community in the group, they gradually get accustomed to this new mode of learning with and through peers. This results in an awareness that this type of learning 'fits and feels good'. They begin to realize that collaboration with a more knowledgeable peer such as a tutor provides them with continuous individual attention and a common focus. This is especially true for the less capable learners. One learner in a tutorial program compared his previous learning experience with his current one in this way:

The teacher concentrates on me and I am able to listen to her. I have never had this back at school. Here it's one-on-one and both are looking at the same paper... [here] I concentrate a lot; I feel very comfortable talking with my tutor.

In tandem with this heightened awareness of group support, the students' beliefs about learning begin to shift. They come to realize that collaborative learning environments require a willingness to create positive interpersonal relationships with their peers by sharing their unique reservoir of knowledge. As the community continues to develop into a respectful environment, there is a high tolerance for mistakes where less capable peers feel more comfortable taking risks. One learner summarized his experience in this way:

I have learned that I learn a lot better in groups than just doing it individually. If I know the answer is wrong and someone else says, 'No, it's the right answer!', then we kinda work back and forth on it. But I find it ... I learn better in groups than individually.

It also seems that, with the continuous intake of students across all types of literacy programs, the community of practice notion of newcomers together with old-timers has some fit with collaborative learning. As newcomers enter this novel type of learning environment, 'old-timers' take them under their wing and create a safety zone so that they can express the changes they feel about group support.

\section{Teaching and learning strategies that favour collaboration}

The next major component in the model consists of the teaching strategies that the instructor draws upon. One key strategy that is often used is the creation of a problem situation in order to raise learners' interests and 
encourage participation and motivation. For example, in another formal literacy program, two instructors brought their large groups together for a problem-solving activity. Using a recent government proposal to cut funding for literacy programs, the teaching strategy put the learners in control by having them prioritize solutions in response to the proposal. As one of the instructors remarked:

We don't necessarily know what the solution would be. It could be an oral solution, it could be a meeting, or it could be a written solution with petitions. The solution is to be determined by what the students arrived at in collaboration.

In both formal and non-formal programs, a common teaching and learning technique was the use of functional literacy content. This consists of identifying real-life activities of direct relevance to a learner or small group. The tutor or instructor then prepares materials based on the level of the learners that focuses on the specific literacy skills that are necessary to learn and practice the new content. Teaching in a non-formal program, the tutor explained it this way:

While you are doing activities that are practical, within these activities there is a lot of skill development going on. Sometimes you have to isolate a skill in order to work on that activity. So for example, in writing a cheque, you need to: understand the form or layout of cheques and why that format is used; to be able to write the date, months of the year, days of the week, number words; write or copy correctly the name of the recipient and be able to write one's signature.

Another teaching and learning strategy was the use of computer technology which helped foster motivation. In another tutorial program the tutor and the learner had previously read an article from an online student newspaper about how a designer shoe factory mistreated its workers in an Asian country. They had also read a first person account by one of the factory workers about how it was hard to make a living in that country. Roger, the learner, had been surprised by the mistreatment and decided to write and type out his response to the story, scaffolded by the tutor.

\section{Phases of cognitive apprenticeship}

When working with dyads and small groups, the instructor may utilise a number of teaching phases commonly referred to as cognitive apprenticeship. For example, he or she might model a behaviour or skill for the more capable learners who then coach other peers to perform that same particular literacy skill. The phases of modelling and coaching were quite 
evident across different types of small group interactions. In one teaching and learning transaction, two female learners, Edith and Danielle, were working on a newspaper article to answer who, what, where, when and why questions set by the instructor. In her role as the more capable learner, Edith was aware of the main goals of the activity, which were to demonstrate to Danielle how to analyze the article based on the five questions. Edith was careful not to provide the answers for Danielle but to model the task and then help Danielle do a similar task. She allowed her to problem solve on her own but under her guidance. In Edith's words, 'I have a good idea of her not copying mine, but doing something in her pages similar to what I have done.'

During the modelling phase, less capable learners primarily watch, listen and closely imitate what the more skilled peers do. In another example, two learners, Julia and Fatima, were busy making muffins after reading a large print recipe which was hanging from the wall. Julia, a more capable learner, was providing assistance to Fatima. Julia explained what Fatima was doing when she was helping her:

She was watching. She was paying attention to my instructions and she was listening to what I was saying and then she would follow the steps.

In the approximating phase, which is another step in the cognitive apprenticeship model, the less capable peer begins to ask for more information and for clarification in performing the steps of the task. During this phase, the more capable learners encourage and relieve tension when progress is slow.

\section{Developing learning independence and autonomy}

In a collaborative learning environment, the roles of both instructor and student gradually change. This change occurs as a student moves from a position of being guided in the learning, to one where he or she experiences some sense of independence and autonomy. During this passage, the instructor moves from transmitting information to facilitating the learning process. When independent learning occurs, engagement in the task is highly concentrated. As students move into this learning mode, they begin to take responsibility for self-monitoring, adjusting plans, selfquestioning and questioning others in the group. This sense of autonomy often leads to a student managing their own learning, reflecting on how they have learned and tapping into a wider range of resources to help achieve a goal.

As a result of the collaborative learning environment, adult learners begin to see the connections between the practice of learning new skills in the classroom or group and the practice and use of literacy skills in the 
world outside. When this happens, some students experience an important personal transformation. This transformation results in a changed positive outlook about themselves, an increase in their confidence and improved selfesteem. These shifts in identity also impact how they view others and their success in other life roles. This shift was captured by the statement of one of the learners when she was talking about the changes she experienced through being part of a small group of learners:

It helps me learn how to communicate with people... how to be more confident in what I'm doing because if I see that I'm helping someone else then that shows that I'm gonna be able to go into a job situation and I'm not gonna just sit back and be all nervous and scared.

Additionally, the UK research found that workplace peers can play an important role in helping those who are under-confident, negative, worried or have low self-esteem. Also, learners can adapt their behaviour to work collaboratively. Peers can play an important role in working with learners who are negative, worried or suffer from low self esteem as in the case of Bill.

Bill was the newest member of the group. He originally came to the computer class and was referred by the tutor because of his dyslexia. He made the least contributions to activities and discussions. When he spoke negatively about collaborative learning, the rest of the group tried to change his mind. David was the most vocal.

\section{No, it's different here. It's not like school. I left school with nothing, I didn't even know the alphabet and I've learnt everything as an adult. It was frightening at work and I bluffed for years and years. I hated writing when I first came but now it's $O K$.}

The tutor is aware of Bill's abilities and his low confidence and includes him by prefacing some questions with his name. She encourages learning independence by getting the capable peers to answer Bill's questions and then builds on their answers. During one lesson, the tutor gave the learners chopped up words in bundles and they worked together to make compound words. She says 'I feel that experimenting with different combinations takes the pressure off as they don't have to actually spell the words themselves'.

A learner from another workplace program, Pat, thinks that collaborative learning is about being co-operative, working with others, and being open-minded to their suggestions. Asked why she thought the tutor encouraged it, she said 'It's the right way forward, getting other peoples' ideas. It builds trust and teamwork and it allows the tutor to get on with other 
things'. Pat said she liked it because she got to know the other members of the class. She felt it built trust and she got other peoples' ideas and views. She said that it helped her to see there were different ways to do things and that when she said something out loud, it 'sunk in'. Pat felt that if her answer was different from her partner's, she could step back and have a look at it. The supportive environment of the class enabled Pat to build her confidence, reflect on her contributions and work towards becoming an independent learner.

\section{Implications for Adult Education practice and theory}

Results of the study provide some new evidence on how adult teaching perspectives and adult learning strategies can form an integrated collaborative framework for improving literacy provisions. For example, findings from both countries have confirmed that collaborative learning practices can help change the viewpoint of learners who have failed or under-achieved in formal education. Results indicate that the sense of being able to influence the learning process by their own inputs and actions ('agency') through collaborative learning promotes positive experiences that further facilitate their learning. Collaborative learning and developmental, nurturing teaching styles appear to build the confidence and the self-esteem needed to enable successful adult learning in community-based and workplace programs. As Evans, Hodkinson, Rainbird and Unwin (2006) point out, communities of learners operate within social frameworks. Outer frameworks are the external constraints or regulatory frameworks that influence learning, for example, the mandatory curriculum frameworks for literacy in both Ontario and the UK. In the workplace context, these outer frameworks involve hierarchies and norms that govern access to learning and participation in particular social practices involving literacy (Lankshear 2000). Inner social frameworks are the cultures operating in the immediate environment of the program and it is these cultures that are more open to influence and change by the actors involved, and impact on how adults learn collaboratively.

A further finding concerns differences between types of adult literacy program milieus - workplace- and community-based. When teaching in the workplace, instructors need to be particularly sensitive to the roles that learners have outside the classroom and appreciate the impact this may have inside the classroom. When a learner has a supervisory or managerial role, it may be difficult for them to have their level of literacy exposed and this may be compounded by asking learners to work collaboratively. Where the whole team attended the same class together, learners appeared to be defined by their work role, the class talk revolved around their work outside and, as they were in working hours, the classroom seemed to be an extension of the workplace even though it was held off site. Contrastingly, 
classes held on work premises but made up of learners from all areas of the business, seemed to enable people to be less affected by their work roles. As their peers were largely unknown to them, so their behaviour was more akin to that of a regular literacy class.

One further implication of this study concerns the theoretical work on teaching philosophies. Currently the literature on teaching philosophies and perspectives is silent on the position of a collaborative approach to teaching in adult basic education. We believe this study opens up a discussion on the status of collaborative learning as a strong and viable teaching approach supported by a rigorous research base. The question raised for further exploration in the field is whether this approach to teaching cuts across, for example, Pratt's (2002) five teaching perspectives or whether it can best be conceived of as a distinct philosophy on its own. Our findings indicate that while the collaborative approach to teaching shares some of the features of other perspectives such as developmental and nuturing, it can be argued that a collaborative teaching style constitutes a unique philosophy unrecognized as such and that it derives from a broader philosophy of teaching with its unique sets of beliefs, actions, and intensions for instructors. For instance, at the level of beliefs, a collaborative philosophy views learning as inherently social and context specific. At the level of actions, teachers need to identify and match learners with differential abilities in pairs or groups. At the level of intentions, drawing on a sociocultural theory of learning (Gee 2000), all knowledge is relational, therefore students need to engage in activities that require them to interact with others. It is through such interaction with others initially more skilled than themselves that they will eventually themselves become knowledgeable peers.

\section{Acknowledgements}

The authors would like to acknowledge the Valuing Literacy in Canada funding program through SSHRC/NLS; the Ottawa-Carleton Catholic School Board and Trudy Lothian; the Ottawa-Carleton District School Board and Christine Pinsent Johnson; the University of Ottawa research assistants; the learners and instructors who took time to participate in the study; Professor John Collins from the University of British Columbia who conducted the quantitative analysis; and Sue Southwood, practitioner fellow from the United Kingdom.

\section{References}

Barton, D, Hamilton, M and Ivanic, R (2000) Situated Literacies, Routledge Press, London.

Evans, K, Hodkinson, P, Rainbird, H and Unwin, L (2006) Improving Workplace Learning, Routledge Press, London. 
Galbraith, M, ed (2004) Adult Learning Methods: A guide for effective instruction, Kreiger Publishing Company, Malabar, FL.

Gee, J (2000) The New Literacy Studies: From socially situated to the work of the social, in Barton, D, Hamilton, M and Ivanic, R, eds, Situated Literacies, Routledge Press, London, UK, pp

Hurby, G (2001) Sociological Postmodern, and New Realism Perspectives in Social Constructionism: Implications for literacy research, Reading Research Quarterly, vol 36, no 1, pp 48-62.

Lankshear, C (2000) Getting Smart Around Literacy, in Gerber, R and Lankshear, C, eds, Training for a Smart Workforce, Routledge Press, London, UK, pp

Maloch, B (2002) Scaffolding Student Talk: One teacher's role in literature discussion groups, Reading Research Quarterly, vol 37, no 1, pp 94-112.

Merriam, S (2002) Qualitative Research in Practice, Jossey-Bass, San Francisco, CA.

O'Connor, M (1998) Can we Trace the Efficacy of Social Constructivism?, Review of Research in Education, vol 23, pp 25-71.

Pratt, D and Associates (2002) Five Perspectives on Teaching in Adult and Higher Education, Kreiger Publishing Company, Malabar, FL.

Rogoff, B (1995) Observing Sociocultural Activity in Three Planes: Participatory appropriation, guided participation and apprenticeship, in Wertsch, J, del Rio, P and Alvarez, A, eds, Sociocultural Studies of the Mind, Cambridge University Press, Cambridge, England.

Statistics Canada (2005) Adult Literacy and Life Skills Survey: Learning and living, Statistics Canada, Ottawa, Canada, (Catalogue No 89603 XWE).

Taylor, M, Abasi, A, Pinsent-Johnson, C and Evans, K (2007) Collaborative Learning as the Catalyst in Communities of Literacy Practice, Adult Basic Education and Literacy Fournal, vol 1, no 1, pp 4-11.

Taylor, M, Evans, K and Abasi, A (2006) Towards a Learning and Teaching Model in Adult Literacy, in English, L and Kroen, J, eds, Proceedings of the 25th Annual Conference of the Canadian Association for the Study of Adult Education, York University, Toronto, Canada, pp 227232.

Taylor, M and Blunt, A (2001) A Situated Cognition Perspective on Literacy Discourses: Seeing more clearly through a new lens, The Canadian Fournal for the Study of Adult Education, vol 15, no 2, pp 79-103.

Taylor, M, King, J, Pinsent-Johnson, C and Lothian, T (2003) Collaborative Practices in Adult Literacy Programs, Adult Basic Education: An interdisciplinary journal for literacy educators, vol 13, no 2, pp 81-99.

Vygotsky, L (1999) Thought and Language, The Massachussets Institute of Technology Press, Cambridge, MA. 
Wenger, E, McDermott, R and Snyder, W (2002) Cultivating Communities of Practice: A guide to managing knowledge, Harvard Business School Press, Boston, MA.

Zinn, L (2004) Exploring your Philosophical Orientation, in Galbraith, M, ed, Adult Learning Methods: A guide for effective instruction, Kreiger Publishing Company, Malabar, FL, pp 133-160. 
